\title{
Evaluasi Kesesuaian Lahan Komoditas Pangan Utama di Kecamatan Umbu Ratu Nggay Barat Kabupaten Sumba Tengah
}

\author{
Evaluation of Land Suitability of Main Food Commodities in West Umbu Ratu Nggay District Central \\ Sumba Region
}

\author{
Marten Umbu Nganji ${ }^{1 *}$, Bistok Hasiholan Simanjuntak ${ }^{2}$, Suprihati ${ }^{3}$ \\ ${ }^{1}$ Jurusan Magister Ilmu Pertanian, Fakultas Pertanian dan Bisnis, Universitas Kristen Satya Wacana, Jl. Diponegoro \\ No. 52-60, Salatiga 50711, Indonesia \\ 2, ${ }^{3}$ Fakultas Pertanian dan Bisnis, Universitas Kristen Satya Wacana, Jl. Diponegoro No. 52-60, Salatiga 50711, \\ Indonesia \\ *Email: 532015001@student.uksw.edu; marthen.tarimbang@gmail.com
}

Tanggal submisi: 8 Februari 2018; Tanggal penerimaan: 31 Mei 2018

\begin{abstract}
ABSTRAK
Penelitian ini dilakukan di Kecamatan Umbu Ratu Nggay Barat Kabupaten Sumba Tengah pada bulan Januari-Maret 2017. Metode analisis yang digunakan adalah metode LQ (Location Quotient), metode pencocokan dan metode overlay. Hasil analisis menunjukkan bahwa komoditas pangan unggulan di Kecamatan Umbu Ratu Nggay Barat secara berturut-turut adalah kacang hijau dengan nilai LQ 1,60, ubi jalar dengan nilai $L Q$ 1,33, padi sawah dengan nilai $L Q$ 1,03 dan jagung dengan Nilai LQ 1,03. Kelas kesesuaian lahan kacang hijau adalah S2 (cukup sesuai) dengan luas $28.021,13$ ha $(99,69 \%)$ dan $N$ (tidak sesuai) 87,91 ha $(0,31 \%)$. Komodias ubi jalar dengan kelas kesesuaian lahan S1 (sangat sesuai) dengan luas 90,41 ha $(0,32 \%)$, S2 (cukup sesuai) dengan luas 27.930,73 ha (99,37\%), dan N (tidak sesuai) 87,91 ha $(0,31 \%)$. Komoditas padi sawah dengan kelas kesesuaian lahan S1 (sangat sesuai) $1.322,43$ ha $(4,70 \%)$. S2 (cukup sesuai) $26.704,21$ ha $(95,00 \%)$, dan $N$ (tidak sesuai) 83,24 ha $(0,30 \%)$. Komoditas jagung dengan kelas kesesuaian lahan S2 (cukup sesuai) $28.021,13$ ha $(99,69 \%)$ dan $N$ (tidak sesuai) 87,91 ha $(0,31 \%)$.
\end{abstract}

Kata Kunci: kesesuaian lahan; komoditas pangan utama; Umbu Ratu Nggay Barat

\begin{abstract}
This research was conducted in West Umbu Ratu Nggay district of Central Sumba Region in January-March 2017. The method of analysis used was LQ (Location Quotient) method, matching method and overlay method. The results showed that the maim food commodities in West Umbu Ratu Nggay District were green beans with values of LQ 1,60; sweet potato with LQ 1,33 , rice with LQ 1,16 ; and corn with LQ 1,03 . Green beans suitability class is S2 (moderatelly suitable) with area $28.021,13 \mathrm{ha}(99.69 \%)$ and $\mathrm{N}$ (not suitable) with area $87.91 \mathrm{ha}(0.31 \%)$. Sweet potato commodity with land suitability is in class S1 (highly suitable) with area 90,41 ha $(0.32 \%)$, S2 (moderatelly suitable) with of $27.930,73$ ha $(99.7 \%)$, and $\mathrm{N}$ (not suitable) with area 87,91 ha $(0.31 \%)$. Commodity of rice with land suitability class S1 (highly suitable) with area of $1.322,43$ ha $(4.70 \%)$, S2 (moderatelly suitable) with area of $26.704,21$ ha $(95.00 \%)$, and $\mathrm{N}$ (not suitable) with area of 83,24 ha $(0.30 \%)$. Corn commodity with land suitability class S2 (moderatelly suitable) with area of $8.021,13 \mathrm{ha}(99.69 \%)$ and $\mathrm{N}$ (not suitable) with area of $87,91 \mathrm{ha}(0.31 \%)$.
\end{abstract}

Keywords: Land suitability; main food commodity; West Umbu Ratu Nggay

\section{PENDAHULUAN}

Pembangunan daerah dapat terlaksana jika potensi sumber daya alam yang tersedia dapat dikelola dan dimanfaatkan secara maksimal. Sektor pertanian merupakan salah satu sektor yang memiliki kontribusi besar terhadap pembangunan daerah dan ekonomi masyarakat. Menurut Faizah \& Santoso (2013) pembangunan daerah dan wilayahnya, tidak lepas dari peran pembangunan sektor pertanian, sehingga perlu adanya peningkatan usaha pertanian agar wilayah atau wilayah tersebut mampu berkembang. Subsektor tanaman pangan yang merupakan bagian dari sektor 
pertanian memiliki peran yang penting dalam rangka peningkatan perekonomian Kabupaten Sumba Tengah. Menurut Hendayana (2003) dan Suharyanto dkk. (2013), dalam menghadapi era pasar global diperlukan penetapan komoditas unggulan nasional dan daerah sebagai salah satu dasar untuk menuju pembangunan pertanian yang berpedoman pada konsep efisiensi untuk mencapai keunggulan kompetitif dan komparatif.

Kabupaten Sumba Tengah merupakan wilayah yang berada pada kawasan dengan karakteristik iklim, tanah dan fisiografi beragam. Keragaman karakteristik lahan tersebut dapat mempengaruhi pertumbuhan dan perkembangan tanaman sehingga berpengaruh pula pada produksi dari tanaman itu sendiri. Tanaman yang tumbuh pada kondisi iklim dan lahan yang sesuai dapat berproduksi secara maksimal, sebaliknya tanaman yang tumbuh pada kondisi iklim dan lahan yang tidak sesuai berdampak pada menurunnya produksi. Menurut Setianto \& Susilowati (2014) keragaman karakteristik fisik lahan dapat dijadikan dasar untuk melakukan pertimbangan dalam menentukan perwilayahan komoditas pertanian. Potensi sumber daya alam seperti iklim, tanah dan hidrologi merupakan ketetapan dalam penggunaan lahan yang dianalisis secara komprehensif (Abagyeh et al., 2016).

Berdasarkan data BPS Kecamatan Umbu Ratu Nggay Barat (2014), luas panen tanaman pangan mengalami penurunan pada tahun 2013 yaitu 3.631 ha dibandingkan pada tahun 2012 sebesar 3.960 ha. Terdapat pula lahan produktif berupa lahan tidur dan tegalan yang belum dimanfaatkan oleh masyarakat dalam mengembangkan tanaman pangan untuk mendukung perekonomian Kabupaten Sumba Tengah. Menurunnya luas panen dan masih terdapat lahan kosong akan berdampak pada menurunnya produksi dan produktivitas tanaman pangan, ditambah lagi dengan belum optimalnya penerapan intensifikasi pertanian. Jika lahan yang tersedia dimanfaatkan secara optimal akan meningkatkan perekonomian wilayah untuk kesejahteraan masyarakat. Pemetaan wilayah pertanian merupakan salah satu cara yang diambil untuk mencapai ketetapan pembudidayaan tanaman pertanian. Menurut Andi (2006) dalam penelitiannya menyebutkan penentuan wilayah akan memberikan gambaran kawasan-kawasan yang akan dibudidayakan dan jenis tanamannya sehingga hubungan secara ekonomis dengan kawasan pengembangan lebih jelas. Kesesuaian lahan perlu diperhatikan untuk kepentingan budidaya tanaman agar mendapatkan pertumbuhan yang optimal, walaupun tanaman bisa tumbuh pada suatu lahan, namun belum tentu pertumbuhannya optimal karena berkaitan dengan kondisi dan karakteristik lahan (Mutiara, 2015). Oleh sebab itu, perlu dilakukan penelitian tentang evaluasi kesesuaian lahan komoditas pangan utama di Kecamatan Umbu Ratu Nggay Barat, Kabupaten Sumba Tengah. Tujuan penelitian adalah mengetahui komoditas pangan utama dan menentukan wilayah-wilayah yang sesuai dalam pengembangan komoditas pangan utama.

\section{METODE PENELITIAN}

\section{Tempat dan Waktu Penelitian}

Pengambilan data primer atau sampel tanah dilaksanakan di Kecamatan Umbu Ratu Nggay Barat, Kabupaten Sumba Tengah pada bulan Januari-Maret 2017 dan dilanjutkan dengan analisis sampel tanah di Laboratorium Tanah, Fakultas Pertanian dan Bisnis, Universitas Kristen Satya Wacana, pada bulan April 2017 sampai Juni 2017.

\section{Alat dan Bahan}

Alat yang digunakan dalam penelitian ini adalah: GPS, alat-alat laboratorium dan sofware Arcview versi 3,2, QGIS versi 2,8. Bahan yang digunakan dalam penelitian ini adalah bahan-bahan laboratorium yang dipakai dalam menganalisis sampel tanah.

\section{Pengumpulan Data}

Penelitian ini menggunakan data primer dan data sekunder. Data primer adalah data yang diperoleh langsung dari lapangan maupun analisis laboratorium. Adapun data primer yang dibutuhkan adalah tekstur tanah, kapasitas tukar kation, C-Organik, $\mathrm{pH}$, potensial redoks, bahan kasar, batuan permukaan, dan ketebalan solum. Data sekunder diperoleh dari Dinas Pertanian Perkebunan dan Kehutanan Kabupaten Sumba Tengah, BAPPEDA Kabupaten Sumba Tengah. Data sekunder yang dibutuhkan adalah peta administrasi, peta kelerengan, peta curah hujan, peta jenis tanah, peta penggunaan lahan, data luas panen dan produksi tanaman pangan, data curah hujan bulanan dan tahunan 10 tahun terakhir.

\section{Metode Analisis}

\section{Analisis komoditas pangan unggulan}

Untuk mengetahui komoditas pangan unggulan Kecamatan Umbu Ratu Nggay Barat Kabupaten Sumba Tengah maka digunakan metode LQ (Location Quotient) produksi tanaman pangan dan luas panen yang mengacu pada persamaan 1 (Bachrein, 2003); lihat Juarsyah dkk., 2015)

$$
\mathrm{LQ}=\frac{\mathrm{Ri} / \mathrm{Rt}}{\mathrm{Ri} / \mathrm{Rt}}
$$

\section{Dimana:}

$\mathrm{LQ}=$ Location Quotient

$R i=$ Nilai produksi komoditi pertanian $\mathrm{i}$ pada wilayah Kecamatan

Rt $=$ Nilai total produksi komoditi pertanian pada tingkat Kecamatan

$\mathrm{Ri}=$ Nilai produksi komoditi pertanian $\mathrm{i}$ pada tingkat Kabupaten

Rt $=$ Nilai total produksi komoditi pertanian pada tingkat Kabupaten

Kriteria pengukuran nilai LQ yang dihasilkan yakni: Bila LQ > 1 maka, komoditas tersebut merupakan komoditas basis atau unggulan, dapat menyediakan pasokan di wilayah bersangkutan dan dapat dipasok ke 
luar daerah.

Bila LQ $<1$ maka, komoditas tersebut bukan komoditas basis atau unggulan, tidak dapat memenuhi kebutuhan wilayah dan harus melakukan pengadaan dari daerah lain. Bila LQ = 1 maka, komoditas tersebut bukan komoditas basis atau unggulan, hanya untuk kebutuhan konsumtif wilayah bersangkutan dan tidak dapat dipasok ke luar daerah.

\section{Analisis kesesuaian lahan}

Evaluasi kesesuaian lahan menggunakan 2 (dua) metode, yaitu: (1) Metode pencocokkan atau matching yaitu membandingkan antara karakteristik lahan sebagai parameter yang diukur di lapangan dan laboratorium dengan kriteria kelas kesesuaian lahan yang disusun berdasarkan persyaratan tumbuh tanaman untuk menentukan faktor pembatas minimum berdasarkan panduan Djaenudin dkk. (2003); (2) Metode overlay dilakukan dengan pemberian skor dan bobot yang berimbang pada karakteristik iklim dan tanah melalui extensios modelbuilder sehingga dapat ditentukan kelas kesesuaian lahan wilayah yang sesuai untuk pengembangan tanaman pangan utama melalui software Arcview 3.2 dan QGIS 2,8. Pemberian skor yang yang berimbang antara karakteristik iklim dan tanah dilakukan dengan asumsi bahwa karakteristik-karakteristik tersebut memiliki pengaruh yang sama terhadap kesesuaian lahan tanaman pangan unggulan. Karakteristik iklim diberi skor 50 yang meliputi suhu udara dan curah hujan, sedangkan karakteristik tanah diberi skor 50 yang meliputi drainase, tekstur, bahan kasar, kedalaman efektif, KTK, pH, COrganik, kelerengan, dan batuan permukaan sehingga diperoleh skor keselurahan parameter pengamatan adalah 100. Pembobotan dilakukan berdasarkan pada kesesuaian karakteristik lahan terhadap kriteria kesesuaian lahan tanaman pangan dengan nilai bobot 4 pada kesesuaian S1, bobot 3 pada kesesuaian S2, bobot 2 pada kesesuaian S3 dan bobot 1 pada kesesuaian $\mathrm{N}$.

\section{HASIL DAN PEMBAHASAN}

\section{Penentuan Komoditas Pangan Unggulan}

Penentuan komoditas pangan unggulan di Kecamatan Umbu Ratu Nggay Barat didasarkan pada metode LQ dengan menggunakan data produksi dan data luas panen. Menurut Hendayana (2003) dan Baladina dkk. (2013), metode LQ sesuai dipakai sebagai metode untuk menentukan komoditas unggulan atau basis khususnya dari aspek populasi maupun produksi. Tanaman pangan, hortikultura, dan perkebunan yang merupakan komoditas berbasis lahan, perhitungannya didasarkan pada luas tanam atau luas panen dan produksi atau produktivitas. Sedangkan komoditas pertanian yang berbasis pada budidaya ternak, dasar perhitungannya didasarkan pada jumlah populasi. Berdasarkan hasil perhitungan LQ, diperoleh komoditas utama di Kecamatan Umbu Ratu Nggay Barat seperti terlihat pada Tabel 1.
Tabel 1. Nilai LQ komoditas pangan di Kecamatan Umbu Ratu Nggay Barat

\begin{tabular}{lcccc}
\hline $\begin{array}{l}\text { Komoditas } \\
\text { pangan }\end{array}$ & $\begin{array}{c}\text { LQ luas } \\
\text { panen }\end{array}$ & $\begin{array}{c}\text { LQ } \\
\text { Produksi }\end{array}$ & $\begin{array}{c}\text { Rata-rata } \\
\text { LQ }\end{array}$ & Ranking \\
\hline Kacang hijau & 1,53 & 1,67 & 1,60 & 1 \\
Ubi jalar & 1,50 & 1,15 & 1,33 & 2 \\
Padi sawah & 1,14 & 1,19 & 1,16 & 3 \\
Jagung & 1,04 & 1,02 & 1,03 & 4 \\
Ubi kayu & 0,63 & 0,62 & 0,63 & 5 \\
Padi ladang & 0,55 & 0,50 & 0,52 & 6 \\
Kedelai & 0,30 & 0,44 & 0,37 & 7 \\
Kacang tanah & 0,15 & 0,53 & 0,34 & 8 \\
\hline
\end{tabular}

Berdasarkan Tabel 1, dari delapan komoditas tanaman pangan di Kecamatan Umbu Ratu Nggay Barat yang dilakukan perhitungan LQ (Location Quotient), diperoleh empat komoditas yang tergolong komoditas utama yang memiliki nilai LQ $>1$. Secara berturut-turut, komoditas tersebut adalah kacang hijau, ubi jalar, padi sawah dan jagung. Penentuan komoditas - komoditas utama tersebut ditentukan berdasarkan rata-rata nilai LQ luas panen dan produksi tanaman pangan di Kecamatan Umbu Ratu Nggay Barat. Hal ini sesuai dengan Zakiah dkk. (2015) dalam penelitiannya menjelaskan bahwa penentuan komoditas unggulan secara berurutan atau perankingan nilai LQ yang tinggi sampai terendah, dilakukan dengan cara merataratakan nilai $L Q$ luas panen dan produksi tanaman. Masih menurut Zakiah dkk. (2015) apabila terdapat nilai LQ produksi lebih besar dari satu, sedangkan LQ luas tanam atau luas panen kurang dari satu atau sebaliknya dengan nilai LQ luas tanam atau luas panen lebih dari satu sedangkan nilai LQ produksi lebih kecil dari satu pada komoditas tertentu, maka komoditas tersebut bukan komoditas unggulan.

Komoditas kacang hijau merupakan komoditas pangan utama yang berada pada ranking pertama dengan nilai $L Q>1$ yaitu 1,60 . Hal ini menunjukkan bahwa komoditas tersebut memiliki potensi keunggulan dan prospek pengembangan yang lebih tinggi dari komoditas lainnya di Kecamatan Umbu Ratu Nggay Barat. Walaupun demikian, dari segi luas panen dan produksi, kacang hijau lebih kecil dari beberapa komoditas yang lain, namun komoditas tersebut memiliki keunggulan karena penentuan komoditas unggulan adalah membandingkan luas panen dan produksi kecamatan dengan luas panen dan produksi kabupaten. Selanjutnya ubi jalar memiliki nilai LQ $>1$ yaitu 1,33 yang merupakan komoditas kedua setelah kacang hijau. Dari segi luas panen, tanaman ubi jalar tergolong tinggi dengan nilai LQ 1,50 namun produksinya sangat minim jika dilihat dari nilai LQ produksinya. Selanjutnya, komoditas padi sawah dan 
jagung merupakan komoditas pangan utama atau basis yang berada pada ranking ketiga dan keempat dengan nilai $L Q>1$ secara berurutan yaitu 1,16 dan 1,04 . Dari segi luas panen dan produksi kecamatan, komoditas padi sawah dan jagung merupakan komoditas yang lebih besar dari komoditas kacang hijau, namun jika dibandingkan dengan rata-rata luas panen dan produksi kecamatan dengan rata-rata luas panen dan produksi kabupaten, maka kacang hijau merupakan komoditas yang memiliki nilai LQ yang lebih besar dan disusul komoditas ubi jalar, padi sawah dan jagung.

Oleh sebab itu hasil analisis location quotient tersebut menggambarkan bahwa komoditas kacang hijau, ubi jalar, padi sawah dan jagung merupakan komoditas utama yang mampu menyiapkan pasokan pangan untuk wilayah Kecamatan Umbu Ratu Nggay Barat, namun demikian perlu dilakukan peningkatan produksi dan produktivitas dengan memanfaatkan lahan-lahan pertanian produktif dan menerapkan sistem intensifikasi pertanian serta dengan memperhatikan kondisi wilayah yang sesuai untuk pengembangan komoditas pangan tersebut.

\section{Kesesuaian Lahan Komoditas Pangan Kacang Hijau}

Berdasarkan analisis kelas kesesuaian lahan metode overlay menggunakan extension modelbuilder, diperoleh dua kelas kesesuaian lahan untuk komoditas kacang hijau di Kecamatan Umbu Ratu Nggay Barat (Gambar 1) yaitu: kelas kesesuaian S2 (cukup sesuai) 28.021,13 ha $(99,69$ $\%$ ) dan $\mathrm{N}$ (tidak sesuai) 87,75 ha $(0,31 \%)$. Hal ini menggambarkan bahwa, Kecamatan Umbu Ratu Nggay Barat merupakan wilayah yang cukup sesuai dalam pengembangan atau budidaya tanaman kacang hijau. Hal ini sesuai dengan data hasil matching parameter karakteristik lahan dengan kriteria kesesuaian lahan komoditas kacang hijau yang menunjukkan bahwa faktor pembatas utama dalam pengembangan komoditas kacang hijau adalah ketersediaan oksigen (oa) atau drainase dan media perakaran (rc) atau kedalaman efektif. Komoditas kacang hijau merupakan komoditas yang tidak cocok pada genangan air atau kondisi drainase yang buruk, apabila selama masa pertumbuhan kacang hijau mengalami kelebihan air, maka akan berdampak pada produksi yang kurang optimal. Untuk menaikan kelas kesesuaian lahan menjadi sangat sesuai maka diperlukan perbaikan faktor pembatas yang menjadi penghambat dalam budidaya tanaman kacang hijau dengan cara pembuatan selokan dan pemambahan bahan organik, usaha ini dilakukan agar kacang hijau sesuai dalam pengembangannya. Menurut Djaenudin dkk. (2003) faktor pembatas ketersediaan oksigen dapat diperbaharui dengan dilakukan perbaikan saluran drainase atau perbaikan ketersediaan oksigen yang mencukupi yang dapat meningkatkan kelasnya sampai kelas terbaik.

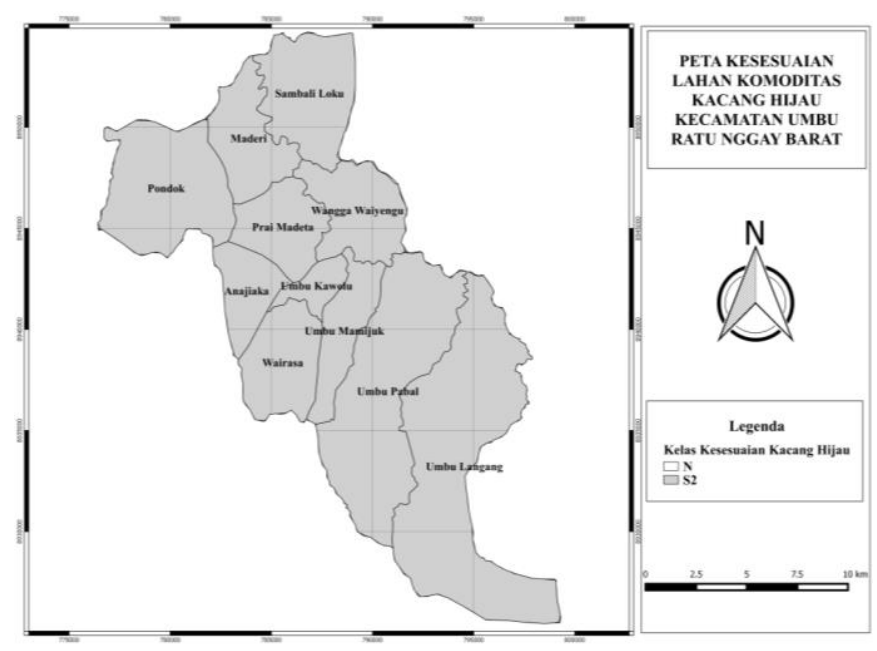

Sumber: Hasil olah data, 2017

Gambar 1. Peta kesesuaian lahan komoditas kacang hijau

\section{Kesesuaian Lahan Komoditas Pangan Ubi Jalar}

Berdasarkan hasil analisis kelas kesesuaian lahan metode overlay menggunakan extension modelbuilder Arcview, diperoleh tiga kelas kesesuaian lahan tanaman ubi jalar di Kecamatan Umbu Ratu Nggay Barat (Gambar 2) yaitu: kelas kesesuaian $S 1$ (sangat sesuai) dengan luas $14.198,66$ ha $(50,51 \%) ; \quad S 2$ (cukup sesuai) $13.819,97$ ha $(49,17 \%)$ dan $N$ (tidak sesuai) 90,24 ha $(0,32 \%)$. Kelas kesesuaian lahan S1 tersebar di semua desa di Kecamatan Umbu Ratu Nggay Barat dengan persentase luas wilayah lebih besar dari kelas kesesuaian lahan S2 namun tidak terlalu berbeda signifikan. Kondisi ini menggambarkan bahwa wilayah yang sangat sesuai (S1) dapat dijadikan wilayah fokus utama dalam pengembangan atau budidaya komoditas ubi jalar sehingga terjadi peningkatan produksi dan produktivitas. Wilayah dengan kelas S2 merupakan wilayah yang cukup sesuai sehingga diperlukan perbaikan faktor pembatas untuk menaikan kelasnya menjadi satu tingkat di atasnya. Pencocokkan atau matching parameter karakteristik lahan dengan kriteria kesesuaian lahan tanaman pangan ubi jalar diperoleh faktor pembatas utama yaitu ketersediaan oksigen (oa) atau drainase, dan media perakaran (rc) atau kedalaman efektif. Faktor pembatas drainase dapat dilakukan perbaikan dengan membuat selokan atau saluran air dan penambahan bahan organik agar tanah dapat mempertahankan kualiatasnya sebagai hasil kerja dari mikroorganisme tanah. Faktor pembatas ketersediaan oksigen dapat diperbaharui dengan dilakukan perbaikan saluran drainase atau perbaikan ketersediaan oksigen yang mencukupi yang akan meningkatkan kelasnya sampai kelas terbaik (Djaenudin dkk., 2003). Untuk faktor pembatas kedalaman efektif, umumnya tidak dapat dilakukan perbaikan jika lapisan yang menghambat tebal dan tidak dapat ditembus (Hardjowigeno \& Widiatmika, 2007; lihat Jayanti dkk., 2013). Tanaman ubi jalar merupakan tanaman yang membutuhkan banyak air, namun tidak pada kondisi tergenang, sehingga dalam membudidayakan komoditas ubi jalar membutuhkan drainase yang baik. 


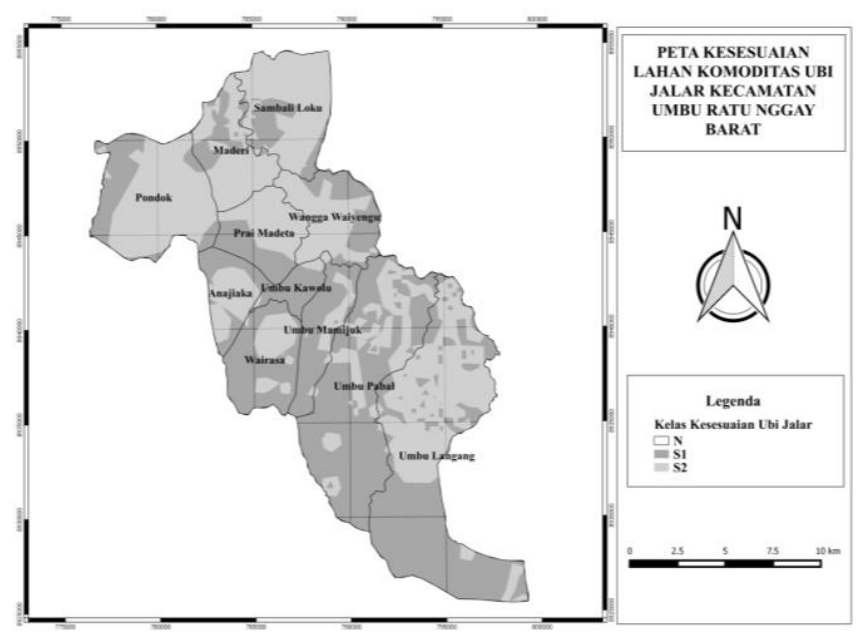

Sumber: Hasil olah data, 2017

Gambar 2. Peta kesesuaian lahan komoditas ubi jalar

\section{Kesesuaian Lahan Komoditas Pangan Padi Sawah}

Berdasarkan analisis kelas kesesuaian lahan metode overlay melalui extension modelbuilder pada Arcview, diperoleh tiga kelas kesesuaian lahan komoditas padi sawah di Kecamatan Umbu Ratu Nggay Barat (Gambar 3) yaitu: kelas kesesuaian S1 (sangat sesuai) dengan luas $4.063,28$ ha $(14,45 \%) ;$ S2 (cukup sesuai) 23.956,90 ha $(85,23 \%)$; dan $N$ (tidak sesuai) 88,69 ha $(0,32 \%)$. Wilayah dengan kelas kesesuaian lahan S1 terdapat di sebagian Desa Pondok, Maderi, Sambali Loku, Umbu Kawolu, Umbu Mamijuk, Wangga Waiyengu, Umbu Pabal dan Umbu Langang. Dalam hal ini, terlihat bahwa Kecamatan Umbu Ratu Nggay Barat merupakan wilayah dengan sebagian besar kelas kesesuaian lahan S2 (cukup sesuai) untuk pengembangan atau budidaya tanaman padi sawah, namun apabila dilakukan perbaikan terhadap faktor pembatas, maka akan naik kelas menjadi S1 (sangat sesuai). Hasil matching parameter karakteristik lahan dengan kriteria kesesuaian lahan komoditas pangan padi sawah diperoleh faktor pembatas utama yaitu ketersediaan oksigen (oa) atau drainase dan media perakaran (rc) atau kedalaman efektif. Faktor pembatas ketersediaan oksigen dapat diperbaharui dengan dilakukan perbaikan saluran drainase atau perbaikan ketersediaan oksigen yang mencukupi yang dapat meningkatkan kelasnya sampai kelas terbaik (Djaenudin dkk., 2003). Komoditas padi sawah pada masa pertumbuhan vegetatif memerlukan air dalam jumlah banyak dan genangan air yang sesuai, namun tidak tergenang dalam waktu yang lama karena akar tanaman padi sawah membutuhkan oksigen dalam melakukan, sehingga dalam budidaya tanaman padi sawah diperlukan drainase yang baik untuk hasil yang optimal. Hal ini sesuai dengan Kementan RI (2013) yang menyebutkan bahwa beberapa tanaman memerlukan drainase terhambat seperti padi sawah, sedangkan tanaman lainnya menghendaki drainase yang baik. Pada kondisi drainase baik, aerasi tanah cukup baik, sehingga oksigen cukup tersedia dalam tanah, dengan demikian akar tanaman dapat berkembang dengan baik, dan mampu menyerap unsur hara secara optimal.

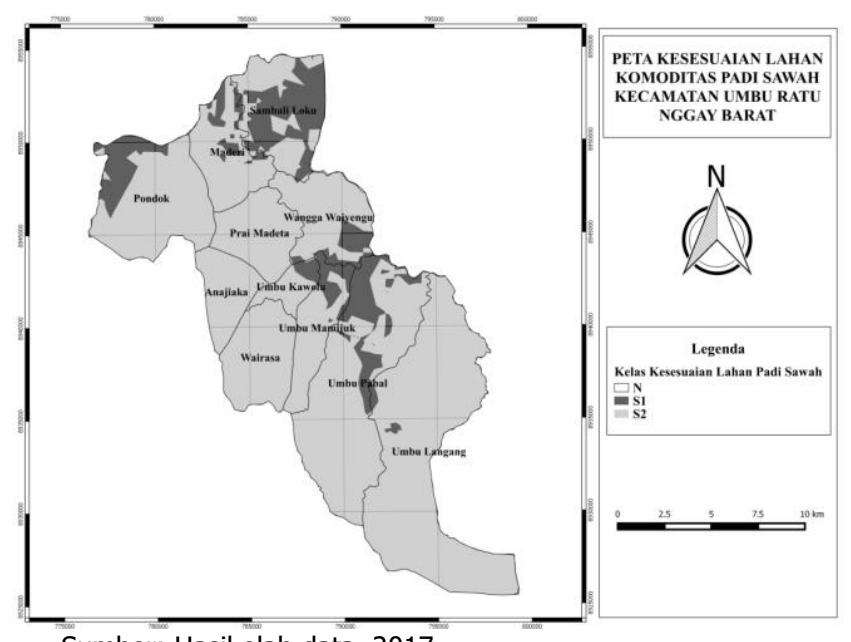

Sumber: Hasil olah data, 2017

Gambar 3. Kelas kesesuaian lahan komoditas padi sawah

\section{Kesesuaian Lahan Komoditas Pangan Jagung}

Berdasarkan hasil analisis kelas kesesuaian lahan metode overlay dengan menggunakan extension modelbuilder pada Arcview, diperoleh dua kelas kesesuaian lahan komoditas jagung di Kecamatan Umbu Ratu Nggay Barat (Gambar 4) yaitu kelas kesesuaian S2 (cukup sesuai) $28.021,13$ ha $(99,69 \%)$ dan N (tidak sesuai) 87,75 ha $(0,31 \%)$. Kelas kesesuaian S2 merupakan kelas kesesuaian yang sangat dominan yang mencakup hampir seluruh wilayah Kecamatan Umbu Ratu Nggay Barat. Kondisi ini menggambarkan bahwa Kecamatan Umbu Ratu Nggay Barat merupakan wilayah yang cukup sesuai untuk budidaya komoditas tanaman pangan jagung. Dari segi produksi, komoditas jagung merupakan komoditas yang berproduksi tinggi setelah padi di Kecamatan Umbu Ratu Nggay Barat, namun produksi akan meningkat apabila dilakukan perbaikan sifat-sifat tanah yang menjadi penghambat dalam pengembangannya. Hasil penilaian parameter karakteristik lahan dengan kriteria kesesuaian lahan komoditas pangan jagung diperoleh faktor pembatas ketersediaan oksigen (oa) atau drainase dan media perakaran (rc) atau kedalaman efektif. Faktor pembatas drainase dapat diperbaiki dengan membuat selokan atau saluran air sehingga ketersediaan air dan oksigen dalam tanah tetap terjaga serta penambahan bahan organik sebagai salah satu cara yang dapat dilakukan agar untuk memperbaiki kualitas tanah. Faktor pembatas ketersediaan oksigen dapat diperbaharui dengan perbaikan saluran drainase dan ketersediaan oksigen yang mencukupi yang dapat meningkatkan kelasnya sampai kelas terbaik (Djaenudin dkk., 2003). Untuk faktor pembatas kedalaman efektif, umumnya tidak dapat dilakukan perbaikan jika lapisan yang menghambat tebal dan tidak dapat ditembus (Hardjowigeno \& Widiatmika, 2007; lihat Jayanti dkk., 2013). 


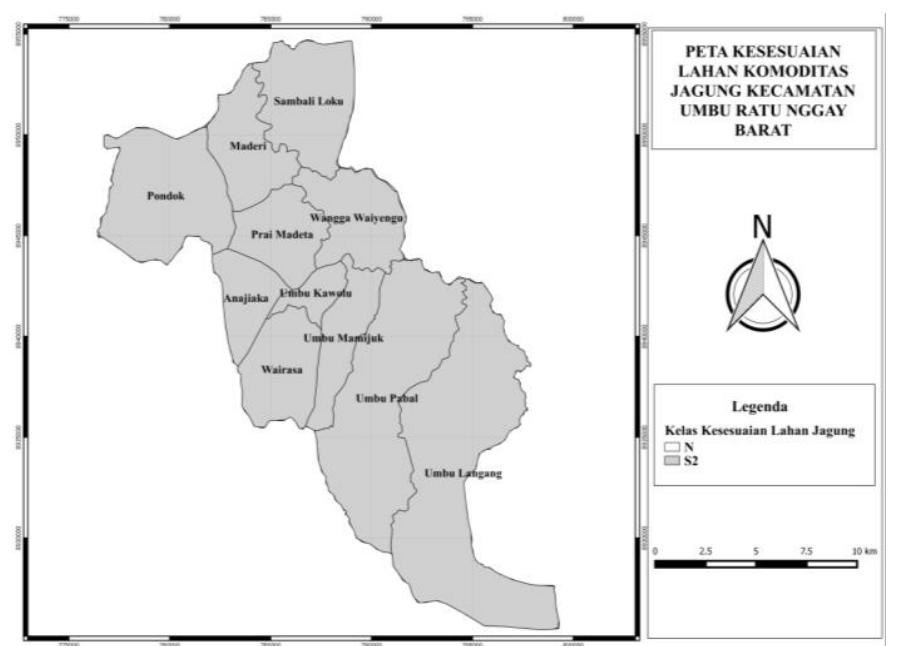

Sumber: Hasil olah data, 2017

Gambar 4. Peta kelas kesesuaian lahan komoditas jagung

\section{KESIMPULAN}

Komoditas pangan utama di Kecamatan Umbu Ratu Nggay Barat berdasarkan nilai LQ adalah kacang hijau, ubi jalar, padi sawah dan jagung. Komoditas-komoditas tersebut merupakan komoditas yang mampu menyiapkan pasokan atas permintaan masyarakat dan menjadi komoditas yang dapat menunjang perekonomian wilayah jika dikembangkan secara tepat. Hasil evaluasi kesesuaian lahan berdasarkan metode overlay karakteristik lahan di kecamatan Umbu Ratu Nggay Barat menunjukkan bahwa kelas kesesuaian lahan tanaman kacang hijau berada pada kelas S2 dan N, komoditas pangan ubi jalar berada pada kelas kesesuaian lahan S1, S2 dan N, komoditas pangan padi sawah berada pada tingkat kelas kesesuaian lahan S1, S2 dam N, sedangkan komoditas pangan jagung berada pada tingkat kelas kesesuaian lahan S2 dan N. Faktor pembatas utama dalam pengembangan tanaman kacang hijau, ubi jalar, padi sawah dan jagung di Kecamatan Umbu Ratu Nggay Barat adalah ketersediaan oksigen (oa) atau drainase dan media perakaran (rc) atau kedalaman efektif.

Pengembangan komoditas pangan utama di Kecamatan Umbu Ratu Nggay Barat harus memperhatikan kesesuaian lahan yang sesuai dan faktorfaktor yang menjadi penghambatnya, sehingga memperoleh hasil yang optimal. Perlu adanya perbaikan atau pembaharuan faktor pembatas komoditas pangan utama, yaitu dengan melakukan perbaikan saluran drainase yang baik sehingga tanaman dapat tumbuh optimal. Perlu adanya input bahan-bahan pertanian untuk mendukung atau menunjang keberlanjutan lahan pertanian dari segi kesuburan dan ketersediaan oksigen dalam tanah, misalnya dengan penambahan bahan organik pada setiap musim tanam.

\section{DAFTAR PUSTAKA}

Abagyeh S. O. I., S, Idoga. and P. I. A. (2016). Land Suitability Evaluation for Maize (Zea mays) Production in Selected Sites
Of the Mid-Benue Valley, Nigeria. International Journal of Agricultural Policy and Research, Vol.4 (3), 46-51.

Andi, P. F. (2006). Arahan Perwilayahan Komoditas Unggulan Di Kabupaten Kotawaringin Timur. Universitas Diponegoro, Semarang.

Bachrein, S. (2003). Penetapan Komoditas Unggulan Propinsi. Jurnal Penelitian. Balai Pengkajian Dan Pengembangan Teknologi Pertanian. Bogor.

Baladina, N., Anindita, R., Isaskar, R. dan Sukardi. (2013). Identifikasi Potensi Komoditi Pertanian Unggulan Dalam Penerapan Konsep Agropolitan Di Kecamatan Poncokusumo, Kabupaten Malang. Agrise, Volume Xii.

Badan Pusat Statistik Daerah Kecamatan Umbu Ratu Nggay Barat. (2014). Kabupaten Sumba Barat.https://sumbatengahkab.bps.go.id/publication/2015 /05/12/60067ddd7275ea2e071c7275/statistik-daerahkecamatan-umbu-ratu-nggay-barat-2014.html [19-032016]

Djaenudin, D., Marwan, H., Subagjo, H. dan Hidayat, A. (2003). Petunjuk Teknis Evaluasi Lahan Untuk Komoditas Pertanian (Edisi Pert). Bogor: Balai Penelitian Tanah, Puslitbangtanak, Balai Penelitian Dan Pengembangan Pertanian.

Faizah, A. A. dan Santoso, E. B. (2013). Arahan Pengembangan Kawasan Pertanian Tanaman Pangan Di Kabupaten Sampang. Jurnal Teknik Its, 2(2), C197-C199. Https://Doi.Org/2337-3539 (2301-9271 Print).

Hardjowigeno, S. dan Widiatmaka. (2007). Evaluasi Kesesuaian Lahan dan Perencanaan Tataguna Lahan. Gadjah Mada University Press, Yogyakarta.

Hendayana, R. (2003). Aplikasi Metode Location Quotient (Lq) Dalam Penentuan Komoditas Unggulan Nasional. Informatika Pertanian, 12.

Jayanti, Dewi Sri., Geonadi, S. dan Hadi, P. (2013). Evaluasi Kesesuaian Lahan Dan Optimasi Penggunaan Lahan Untuk Pengembangan Tanaman Kakao ( Theobroma Cacao L .) ( Studi Kasus Di Kecamatan Batee Dan Kecamatan Padang Tiji Kabupaten Pidie Propinsi Aceh ). Agritech, 33(2), 208218.

Juarsyah, R., Muani, Ani. dan Suyatno, A. (2015). Kajian Pengembangan Agribisnis Komoditas Unggulan BuahBuahan Di Kabupaten Kubu Raya. Jurnal Social Economic Of Agriculture, Volume 4, 56-69.

Kementan RI. (2013). Pedoman Kesesuaian Lahan Pada Komoditas Tanaman Pangan, 1-21. http://perundangan.pertanian.go.id/admin/file/Permentan \%20No.79\%20Tahun\%202013.pdf. [01-02-2018]

Mutiara, E. (2015). Kesesuaian Lahan Untuk Tanaman Kacang Tanah Di Desa Sampuran, Kecamatan Ranto Baek, Kabupaten Mandailing Natal. Jurnal Nasional Ecopedon Jnep, Vol. 2.

Setianto, P. dan Susilowati, I.(2014). Komoditas Perkebunan Unggulan Yang Berbasis Pada Pengembangan Wilayah Kecamatan Di Kabupaten Banjarnegara Provinsi Jawa Tengah, 2, 143-156.

Suharyanto., Agustian. A., dan Parlidungan, Y. S. (2013). Analisis Daya Saing Komoditas Perkebunan Di Kabupaten Kaimana Provinsi Papua Barat. Sepa, Vol. 10 No, 148- 155.

Zakiah., Safrida. \& Santri, L. (2015). Pemetaan Komoditas Unggulan Sub Sektor Perkebunan Di Kabupaten Aceh Selatan. Agrisep, 16(1), 35-52. 